\title{
PENGGUNAAN RATA-RATA ARITMETIKA DENGAN APPROKSIMASI CURRAN DALAM MENENTUKAN HARGA OPSI ASIA
}

\author{
Steffany Harwella \\ Program Studi Matematika, \\ Fakultas Matematika dan Ilmu Pengetahuan Alam, Universitas Andalas, \\ Kampus UNAND Limau Manis Padang, Indonesia, \\ h.steffany@ymail.com
}

\begin{abstract}
Abstrak. Opsi Asia adalah opsi dimana payoff bergantung pada rata-rata harga aset selama opsi tersebut berlaku. Dalam menentukan harga opsi Asia dapat digunakan ratarata aritmatika. Ketika harga saham berdistribusi lognormal, maka rata-rata aritmatika harga sahamnya tidak berdistribusi lognormal. Hal ini mengakibatkan dalam menentukan harga opsi Asia tidak dapat menggunakan model black-Scholes maka perlu dilakukan aproksimasi. Salah satu metode aproksimasi yang bisa dilakukan adalah aproksimasi Curran yang merupakan penentuan opsi Asia menggunakan rata-rata aritmatika melalui pendekatan rata-rata geometrik.
\end{abstract}

Kata Kunci: Opsi Asia, rata-rata Aritmatika, rata-rata geometrik, lognormal, Aproksimasi Curran

\section{Pendahuluan}

Dalam dunia pasar modal pemilik aset melakukan investasi untuk meminimalisir kerugian dalam penjualan atau pembelian sejumlah aset. Salah satu produk investasi yang menarik adalah saham. Selain berinvestasi dengan memiliki secara langsung saham yang diperdagangkan di pasar, investor juga dapat berinvestasi dengan cara membeli turunan dari nilai saham yang disebut dengan pasar derivatif (financial derivative). Produk pasar derivatif yang banyak diperjualbelikan adalah opsi.

Opsi adalah sebuah kontrak antara dua pihak yang memberikan kepada pembeli hak, bukan kewajiban untuk membeli atau menjual sejumlah saham pada harga tertentu yang ditentukan sekarang untuk transaksi yang akan terjadi dimasa yang akan datang. Dalam kontrak opsi, pemilik opsi memiliki resiko kerugian yaitu menjual saham dengan harga lebih rendah atau membeli harga saham lebih tinggi dibandingkan dengan harga saham pada pasar modal. Oleh karena itu harga opsi ditentukan untuk meminimalisasi kerugian tersebut. Masalah perhitungan harga opsi (option pricing) adalah menghitung harga yang wajar (fair value) dimana opsi bisa dibeli atau dijual.

Opsi eksotik merupakan opsi yang memberikan keuntungan yang lebih besar daripada opsi standar, salah satu contohnya adalah opsi barrier yang mana payoff-nya selama masa berlaku opsi bergantung pada nilai aset. Selain opsi barrier, 
opsi eksotik lainnya adalah lookback opsi dan opsi Asia. Opsi Asia adalah opsi yang payoff-nya bergantung pada rata-rata harga aset selama masa berlaku opsi. Perhitungan harga opsi Asia dapat menggunakan rata-rata geometrik dan ratarata aritmatika. Ketika harga saham berdistribusi lognormal, maka rata-rata geometrik harga sahamnya juga harus berdistribusi lognormal, sedangkan distribusi pada rata-rata aritmatika harga sahamnya tidak diketahui. Hal ini mengakibatkan rata-rata aritmatika tidak memenuhi salah satu asumsi dari model Black-Scholes yaitu harga aset berdistribusi lognormal. Akibatnya, perlu dilakukan aproksimasi distribusi rata-rata artimatika. Beberapa metode yang dapat digunakan untuk mengaproksimasi distribusi rata-rata aritmatika tersebut ialah aproksimasi Turnbull dan Wakemann, aproksimasi Levy, aproksimasi Curran, dan Monte Carlo valuation. Metode yang digunakan dalam paper ini adalah aproksimasi Curran yaitu penggunaan rata-rata aritmatika dengan pendekatan rata-rata geometrik.

\section{Konsep Dasar}

Opsi saham adalah suatu opsi dengan aset yang mendasarinya adalah saham. Berdasarkan hak yang diberikan kepada pemilik opsi, opsi dibedakan menjadi dua, yaitu opsi call adalah suatu opsi yang memberi hak kepada pemegangnya untuk membeli sejumlah tertentu saham pada harga tertentu setiap waktu sampai suatu tanggal jatuh tempo atau berakhirnya kontrak opsi, dan opsi put adalah suatu opsi yang memberikan hak kepada pemegangnya untuk menjual sejumlah tertentu saham pada harga tertentu setiap waktu sampai tanggal jatuh tempo atau berakhirnya kontrak opsi.

Tingkat pengembalian (return) yang diharapkan adalah laba yang akan diterima oleh pemodal atas investasinya dalam waktu yang akan datang. Return dihitung dengan rasio harga saham pada waktu $t+1$ dengan harga saham pada waktu $t$. Logaritma natural sampel return pada $t$ hingga $t+1$ dapat dinyatakan sebagai:

$$
\hat{R}_{t}=\ln \frac{S_{t+1}}{S_{t}} ; \quad t=1,2,3, \cdots, n-1
$$

dimana $n$ adalah banyaknya hari perdagangan saham dan $S_{t}$ adalah harga saham pada waktu ke-t.

Dalam menentukan Opsi Asia digunakan rata-rata aritmatika dan rata-rata geometrik, dimana $A \geq G$ dengan A adalah rata-rata aritmatika dan $\mathrm{G}$ adalah ratarata geomterik. Jika $\mathrm{A}$ dan $\mathrm{G}$ peubah acak kontinu saling bebas, maka nilai harapan bersyaratnya menjadi:

$$
E(G \mid a)=E(G) \text { dan } E(A \mid g)=E(A) .
$$

\section{Model Harga Saham}

Perubahan harga saham terjadi secara acak menurut waktu sehingga dapat diasumsikan sebagai suatu proses stokastik. Misalkan $X(t)$ mengikuti proses Wiener, maka $X(t)$ dapat dikembangkan menjadi persamaan pada proses Ito. Proses Wiener merupakan proses stokastik dimana harga saat ini berpengaruh untuk memprediksi 
harga yang akan datang. Harga saham dilambangkan dengan $S$ dan waktu dilambangkan dengan $t$. Maka perubahan harga saham dapat ditulis sebagai:

$$
d S(t)=\mu S(t) d t+\sigma S(t) d W(t) .
$$

Selanjutnya persamaan diferensial stokastik bagi fungsi $X(t)$ dapat dinyatakan dalam bentuk

$$
d X(t)=\left(\mu S(t) \frac{\partial f}{\partial s}+\frac{\partial f}{\partial t}+\frac{1}{2} \sigma^{2} S(t)^{2} \frac{\partial^{2} f}{\partial s^{2}}\right) d t+\sigma S(t) \frac{\partial f}{\partial s} d W(t) .
$$

Salah satu asumsi Black-scholes yaitu harga aset yang mendasari mengikuti proses Wiener yang mempunyai distribusi lognormal dengan parameter mean dan varian yang diketahui dan konstan. Logaritma harga saham pada saat jatuh tempo mempunyai sebaran normal dengan $\mu=\ln S(0)+\left(r-\frac{\sigma^{2}}{2}\right) T$ dan $\operatorname{Var}=\sigma^{2} T$.

\section{Karakteristik Rata-rata Aritmatika dan Karakteristik Rata-rata Geometrik dari Harga Saham}

Ketika harga saham berdistribusi lognormal, maka rata-rata aritmatika harga sahamnya tidak terdistribusi lognormal. Namun, rata-rata geometrik harga saham berdistribusi lognormal yang dapat ditulis sebagai:

$$
\ln \left(\left(\prod_{i-1}^{n} S\left(t_{i}\right)\right)^{\frac{1}{n}}\right) \sim N\left(\ln S(0)+\left(\hat{\mu}-\frac{1}{2} \hat{\sigma}^{2}\right) T, \hat{\sigma}^{2} T\right)
$$

Oleh karena itu, penghitungan opsi Asia menggunakan rata-rata aritmatika dapat dilakukan dengan pendekatan rata-rata geometrik.

\section{Pembentukan Model Opsi Call Asia dan Opsi Put Asia Menggunakan Aproksimasi Curran}

Metode Curran merupakan salah satu aproksimasi menggunakan rata-rata aritmatika dengan melakukan pendekatan rata-rata geometrik. Sehingga Persamaan opsi call dan opsi putnya dapat ditulis menjadi:

$$
\begin{aligned}
& C \approx e^{-r T} \tilde{E}[\tilde{E}[\max (A-K, 0) \mid G]], \text { dan } \\
& P \approx e^{-r T} \tilde{E}[\tilde{E}[\max (K-A, 0) \mid G]]
\end{aligned}
$$

dimana C : Harga opsi call Asia, P : Harga opsi put Asia, E : Taksiran ekspektasi, $\mathrm{r}$ : Tingkat suku bunga bebas resiko, $\mathrm{T}$ : Waktu jatuh tempo, A : Rata-rata aritmatika dari harga saham, G : Rata-rata geomterik dari harga saham, K : Harga pelaksanaan.

Pada jurnal ini hanya dijelaskan tentang pembentukan model opsi call Asia. Selanjutnya menggunakan definisi ekpektasi, persamaan opsi call Asia diatas dapat ditulis menjadi:

$$
C \approx e^{-r T} \int_{0}^{\infty} \tilde{E}[\max (a-K, 0) \mid g] p(g) d g
$$


dengan $\mathrm{p}(\mathrm{g})$ adalah fungsi kepekatan peluang dari variabel random $\mathrm{G}$, yang dapat ditulis:

$$
p(g)=\frac{1}{g \hat{\sigma} \sqrt{2 \pi T}} \exp \left[-\frac{1}{2}\left(\frac{\ln g-\ln S(0)-\left(\hat{\mu}-\frac{1}{2} \hat{\sigma}^{2}\right) T}{\hat{\sigma} \sqrt{T}}\right)^{2}\right]
$$

Berdasarkan pertidaksamaan rata-rata aritmatika dan rata-rata geometrik yang menyatakan bahwa $A \geq G$ untuk semua kemungkinan harga saham, maka ilai G berada pada interval $K \leq G<\infty$ dan $0 \leq G \leq K$. Jika $A \geq G$ dan $G \geq K$, maka $A \geq G \geq K$, dan dapat disimpulkan bahwa $A \geq K$ sehingga nilai payoff nya dapat dicari. Jika $A \geq G$, maka akan menghasilkan dua kemungkinan yaitu $A \geq K$ atau $A \leq K$, dan opsi mungkin akan berakhir pada posisi out of the money. Hal ini menyebabkan kerugian karena holder membeli saham dengan harga di atas harga pasar. Oleh karena itu, persamaan (5.1) menjadi:

$$
\begin{aligned}
C & \approx e^{-r T} \int_{k}^{\infty} \tilde{E}[\max (a-K, 0) \mid g] p(g) d g \\
& =e^{-r T} \int_{k}^{\infty}(\tilde{E}[a \mid g]-\tilde{E}[K \mid g]) p(g) d g \\
& =e^{-r T} \int_{k}^{\infty}(\tilde{E}[a \mid g]-K) p(g) d g
\end{aligned}
$$

Misalkan $X_{i}=\ln S\left(t_{i}\right)$, dimana $X_{i} \sim N\left(\mu_{i}, \sigma_{i}^{2}\right)$ dengan $i=1,2, \cdots, n$ dan $X=\ln G$ dimana $\mathrm{G}$ adalah rata-rata geometrik harga saham, maka:

$$
\begin{aligned}
\tilde{E}\left[S\left(t_{i}\right) \mid G\right] & =E\left[S\left(t_{i}\right)\right] \\
& =\exp \left(\hat{\mu}_{i}+\frac{\hat{\sigma}_{i}^{2}}{2}\right)
\end{aligned}
$$

dan ekpektasi bersyarat diatas dapat ditulis:

$$
\tilde{E}\left[S\left(t_{i}\right) \mid G\right]=\exp \left(\mu_{i}+\left[\frac{\sigma_{x_{i}}}{\sigma_{x}^{2}}\right]\left(x-\mu_{x}\right), \sigma_{i}^{2}-\frac{\sigma_{x_{i}}^{2}}{\sigma_{x}^{2}} / 2\right)
$$

Selanjutnya misalkan $X=\ln G$, maka diperoleh $g d x=d g$, sehingga persamaan (5.2) menjadi:

$$
C \approx e^{-r T} \int_{\ln K}^{\infty}(\tilde{E}[a \mid X=x]-K) f(x) d x
$$

dimana $f(x)$ adalah fungsi kepekatan peluang dari variabel random $\mathrm{x}$.

Jika $A=\frac{1}{n} \sum_{i}^{n} S\left(t_{i}\right)$, maka persamaan (4.3.9) dapat ditulis menjadi :

$$
\begin{aligned}
C & \approx e^{-r T} \int_{\ln K}^{\infty}\left(\tilde{E}\left[\frac{1}{n} \sum_{i=1}^{n} S\left(t_{i}\right) \mid X=x\right]-K\right) f(x) d x \\
& =e^{-r T} \int_{\ln K}^{\infty}\left(\sum_{i=1}^{n} \frac{1}{n} \tilde{E}\left[S\left(t_{i}\right) \mid X=x\right]\right)-K f(x) d x \\
& =e^{-r T} \frac{1}{n} \int_{\ln K}^{\infty} \sum_{i=1}^{n} \tilde{E}\left[S\left(t_{i}\right) \mid X=x\right] f(x) d x-\int_{\ln K}^{\infty} K f(x) d x
\end{aligned}
$$


74 Steffany Harwella

Misalkan

$$
\begin{aligned}
I_{1} & =\frac{1}{n} \int_{\ln K}^{\infty} \sum_{i=1}^{n} \tilde{E}\left[S\left(t_{i}\right) \mid X=x\right] f(x) d x \\
I_{2} & =\int_{\ln K}^{\infty} K f(x) d x
\end{aligned}
$$

- Langkah pertama adalah menghitung $I_{1}$

Subtitusi persamaan (5.3) kedalam persamaan $I_{1}$, maka

$$
I_{1}=\frac{1}{n} \sum_{i=1}^{n} \int_{l n K}^{\infty} \exp \left(\mu_{i}+\left[\frac{\sigma_{x_{i}}}{\sigma_{x}^{2}}\right]\left(x-\mu_{x}\right)\left(\sigma_{i}^{2}-\frac{\sigma_{x_{i}}^{2}}{\sigma_{x}^{2}}\right) / 2\right) f(x) d x
$$

Subtitusi persamaan bentuk $f(x)$ kedalam persamaan (5.6), maka diperoleh

$$
\begin{aligned}
I_{1}= & \frac{1}{n} \sum_{i=1}^{n} \int_{l n K}^{\infty} \exp \left(\mu_{i}+\left[\frac{\sigma_{x_{i}}}{\sigma_{x}^{2}}\right]\left(x-\mu_{x}\right)\left(\sigma_{i}^{2}-\frac{\sigma_{x_{i}}^{2}}{\sigma_{x}^{2}}\right) / 2\right) \frac{1}{\sigma_{x} \sqrt{2 \pi}} \\
& \exp \left[-\frac{1}{2}\left(\frac{x-\mu_{x}}{\sigma_{x}}\right)^{2}\right] d x \\
& \exp \left(\frac{\sigma_{x_{i}}}{\sigma_{x}^{2}} x-\frac{\sigma_{x_{i}}}{\sigma_{x}^{2}} \mu_{x}-\frac{\sigma_{x_{i}}^{2}}{2 \sigma_{x}^{2}}-\frac{1}{2}\left(\frac{x-\mu_{x}}{\sigma_{x}}\right)^{2}\right) d x
\end{aligned}
$$

Selanjutnya misalkan juga

$$
\begin{aligned}
Q & =\exp \left(\frac{\sigma_{x_{i}}}{\sigma_{x}^{2}} x-\frac{\sigma_{x_{i}}}{\sigma_{x}^{2}} \mu_{x}-\frac{\sigma_{x_{i}}^{2}}{2 \sigma_{x}^{2}}-\frac{1}{2}\left(\frac{x-\mu_{x}}{\sigma_{x}}\right)^{2}\right) \\
& =\exp \left(\frac{-\frac{1}{2}\left(x-\mu_{x}-\sigma_{x_{i}}\right)^{2}}{\sigma_{x}}\right)
\end{aligned}
$$

dan

$$
\begin{aligned}
q & =\frac{x-\mu_{x}-\sigma_{x_{i}}}{\sigma_{x}} \\
\sigma_{x} d q & =d x
\end{aligned}
$$

Dengan menggunakan persamaan (5.8) dan $d x=\sigma_{x} d q$, maka persamaan (4.3.13) dapat ditulis menjadi:

$$
I_{1}=\frac{1}{n} \sum_{i=1}^{n} \exp \left(\mu_{i}+\frac{\sigma_{i}^{2}}{2}\right) \int_{\frac{\ln K-\mu_{x}-\sigma_{x}}{\sigma_{x}}}^{\infty} \frac{1}{\sqrt{2 \pi}} \exp \left(-\frac{1}{2} q^{2}\right) d q
$$

Berdasarkan sifat kesimetrisan distribusi Normal, maka

$$
\begin{aligned}
I_{1} & =\frac{1}{n} \sum_{i=1}^{n} \exp \left(\mu_{i}+\frac{\sigma_{i}^{2}}{2}\right) \int_{-\infty}^{\frac{\ln K-\mu_{x}-\sigma_{x_{i}}}{\sigma_{x}}} \frac{1}{\sqrt{2 \pi}} \exp \left(-\frac{1}{2} q^{2}\right) d q \\
& =\frac{1}{n} \sum_{i=1}^{n} \exp \left(\mu_{i}+\frac{\sigma_{i}^{2}}{2}\right) \times N\left[\frac{\ln K-\mu_{x}}{\sigma_{x}}+\frac{\sigma_{x_{i}}}{\sigma_{x}}\right]
\end{aligned}
$$


- Langkah kedua menghitung $I_{2}$ Dengan cara yang sama dengan menghitung $I_{1}$, maka

$$
\begin{aligned}
I_{2} & =\int_{\ln K}^{\infty} K f(x) d x \\
& =\int_{\ln K}^{\infty} K \frac{1}{\sigma_{x} \sqrt{2 \pi}} \exp \left[-\frac{1}{2}\left(\frac{x-\mu_{x}}{\sigma_{x}}\right)^{2}\right] d x
\end{aligned}
$$

Misalkan,

$$
\begin{aligned}
r & =\frac{x-\mu_{x}}{\sigma_{x}} \\
d x & =\sigma_{x} d r
\end{aligned}
$$

maka diperoleh,

$$
\begin{aligned}
I_{2} & =K \int_{-\infty}^{\frac{\ln K-\mu_{x}}{\sigma_{x}}} \frac{1}{\sigma_{x} \sqrt{2 \pi}} \exp \left(-\frac{1}{2} r^{2}\right) \sigma_{x} d r \\
& =K N\left(\frac{\ln K-\mu_{x}}{\sigma_{x}}\right)
\end{aligned}
$$

Setelah diperoleh nilai $I_{1}$ dan $I_{2}$, maka diperoleh nilai opsi call asia menggunakan rata-rata aritmatika melalui pendekatan rata-rata geometrik yaitu:

$C \approx e^{-r T}\left(\frac{1}{n} \sum_{i=1}^{n} \exp \left(\mu_{i}+\frac{\sigma_{i}^{2}}{2}\right) \times N\left(\frac{\ln K-\mu_{x}}{\sigma_{x}}+\frac{\sigma_{x_{i}}}{\sigma_{x}}\right)-K N\left(\frac{\ln K-\mu_{x}}{\sigma_{x}}\right)\right)$

Dan untuk Opsi put diperoleh bentuk model opsi yaitu:

$$
P \approx e^{-r T}\left(K N\left(\frac{\ln K-\mu_{x}}{\sigma_{x}}\right)-\frac{1}{n} \sum_{i=1}^{n} \exp \left(\mu_{i}+\frac{\sigma_{i}^{2}}{2}\right) N\left(\frac{\ln K-\mu_{x}-\sigma_{x_{i}}}{\sigma_{x}}\right)\right)
$$

\section{Penerapan Model Harga Opsi Call dan Opsi Put untuk Saham Tipe Asia}

Dalam penerapan model harga opsi Asia ini, data yang digunakan adalah data harga penutupan harian saham Yahoo!.Inc (YHOO) pada tanggal 29 Agustus 2013 sampai 29 Agustus 2014 yang diakses langsung dari http://www.yahoo-finance.com.

Faktor yang diperlukan dalam perhitungan model yaitu, volatisitas return saham yaitu $\sigma=\sqrt{n \hat{R}}=0.31084$ dengan $R=\frac{\sum_{t-1}^{n} \hat{R}_{t}}{n}=0.00136$ dan $\hat{R}=$ $\frac{\sum_{t-1}^{n}\left(\hat{R}_{t}-R\right)^{2}}{n-1}=0.00038$. Harga saham awal $(S(0)): 38.51$, waktu sekarang $(t)$ : 02 September 2014, waktu jatuh tempo : 20 September 2014, yang berarti $T=\frac{18}{365}=0.04932$. Tingkat suku bunga bebas resiko $(r): 0.025$, dan Harga pelaksanaan $(K): 25.00,30.00,35.00,40.00,45.00,50.00$.

Perhitungan harga opsi call dan opsi put dengan menggunakan aproksimasi Curran untuk harga pelaksanaan 35.00. Nilai $\sigma_{x}^{2}=\frac{\sigma^{2}(n+1)(2 n+1)}{6 n^{2}}=0.03240$, nilai $\mu_{x}=\frac{1}{2} \sigma^{2}+\left(r-\frac{1}{2} \sigma^{2}\right) \frac{n+1}{2 n}=0.06001, \sigma_{i}^{2}=\sigma_{x}^{2} T=0.00160, \mu_{i}=\ln S(0)+$ 
$\left(\mu_{x}-\frac{1}{2} \sigma_{x}^{2}\right) T=3.65308$. Selanjutnya akan dilakukan perhitungan dengan menggunakan software microsoft excel dengan perintah NORMSDIST. Sehingga diperoleh, $C \approx 3.61$ dan $P \approx-3.61=0$. Selanjutnya dengan cara yang sama diperoleh harga opsi call dan opsi put untuk harga pelaksanaan yang berbeda yaitu:

\begin{tabular}{|c|c|c|c|c|}
\hline No & Harga Opsi Call & Harga Opsi Call & Harga Opsi Put & Harga Opsi Put \\
\hline & Hitung Curran & di Pasar Saham & Hitung Curran & di Pasar Saham \\
\hline 1 & 13.60 & 16.70 & 0.00 & 0.02 \\
\hline 2 & 8.61 & 12.50 & 0.00 & 0.02 \\
\hline 3 & 3.62 & 7.53 & 0.00 & 0.02 \\
\hline 4 & 0.00 & 2.85 & 1.38 & 0.34 \\
\hline 5 & 0.00 & 0.51 & 6.37 & 2.99 \\
\hline 6 & 0.00 & 0.06 & 11.37 & 6.85 \\
\hline
\end{tabular}

Perbandingan harga opsi yang dihitung menggunakan aproksimasi Curran dengan harga opsi dipasar saham dapat menjadi acuan untuk para investor.

Untuk semua harga pelaksanaan, sebaiknya investor tidak membeli opsi call karena harga opsi call yang dihitung dengan aproksimasi Curran lebih tinggi daripada harga opsi call dipasaran. Sedangkan untuk opsi put, pada harga pelaksanaan 45.00 dan 50.00 dolar sebaiknya investor tidak menjual opsi put pada harga tersebut, karena harga opsi di pasaran lebih rendah dibandingkan harga opsi put yang dihitung dengan aproksimasi Curran. Sebaliknya pada harga pelaksanaan 25.00, 30.00, 35.00, 40.00 dolar.

\section{Penutup}

Opsi Asia adalah opsi dimana payoff bergantung pada rata-rata harga aset selama opsi tersebut berlaku. Dalam menentukan harga opsi Asia menggunakan rata-rata aritmatika tidak dapat dilakukan dengan model Black-Scholes karena karakteristik dari rata-rata aritmatika tidak berdistribusi lognormal. Oleh karena itu dilakukan aproksimasi Curran yaitu pendekatan rata-rata geometrik dengan

$$
\ln \left(\left(\prod_{i=1}^{n} S\left(t_{i}\right)\right)^{\frac{1}{n}}\right) \sim N\left(\ln S(0)+\left(\hat{\mu}-\frac{1}{2} \hat{\sigma}^{2}\right) T, \hat{\sigma}^{2} T\right)
$$

sehingga diperoleh model aproksimasi Curran sebagai berikut:

$$
\begin{gathered}
C \approx e^{-r T}\left(\frac{1}{n} \sum_{i=1}^{n} \exp \left(\mu_{i}+\frac{\sigma_{i}^{2}}{2}\right) \times N\left(\frac{\ln K-\mu_{x}}{\sigma_{x}}+\frac{\sigma_{x_{i}}}{\sigma_{x}}\right)-K N\left(\frac{\ln K-\mu_{x}}{\sigma_{x}}\right)\right) \\
P \approx e^{-r T}\left(K N\left(\frac{\ln K-\mu_{x}}{\sigma_{x}}\right)-\frac{1}{n} \sum_{i=1}^{n} \exp \left(\mu_{i}+\frac{\sigma_{i}^{2}}{2}\right) \times N\left(\frac{\ln K-\mu_{x}-\sigma_{x_{i}}}{\sigma_{x}}\right)\right)
\end{gathered}
$$


dengan,

$$
\begin{aligned}
\mu_{i} & =\ln S(0)+\left(\mu_{x}-\frac{1}{2} \sigma_{x}^{2}\right) T \\
\sigma_{i} & =\sigma_{x}^{2} T \\
\mu_{x} & =\frac{1}{2} \sigma^{2}+\left(r-\frac{1}{2} \sigma^{2}\right) \frac{n+1}{2 n} \\
\sigma_{x}^{2} & =\frac{\sigma^{2}(n+1)(2 n+1)}{6 n^{2}} \\
\sigma_{x_{i}}^{2} & =\sigma_{x}^{2}\left((i+1)-\frac{i(i+1)}{2 n}\right)
\end{aligned}
$$

Model aproksimasi Curran harga opsi Asia diterapkan pada saham Yahoo!.Inc. Perhitungan harga opsi ini bisa digunakan sebagai acuan oleh para investor dalam pelaksanaan opsi, agar bisa meminimalisir kerugian dalam mengelola aset.

\section{Ucapan Terima kasih}

Penulis mengucapkan terima kasih kepada Bapak Dr. Dodi Devianto, Ibu Izzati Rahmi HG, M.Si, Ibu Hazmira Yozza, M.Si, Bapak Yudiantri Asdi, M.Sc yang telah memberikan masukan dan saran sehingga paper ini dapat diselesaikan dengan baik.

\section{Daftar Pustaka}

[1] Adams, A. 2003. Investment Mathematics. Canada:John Wiley and Sons Ltd.

[2] Anton,H. 1991. Aljabar Linier Elementer Edisi 8, Jilid 1. Erlangga, Jakarta.

[3] Bain, Lee J and Max.E. 1992. Introduction To Probability and Mathematical Statistics Second Edition. California: Duxbury Press.

[4] Walpole, RE. 1993. Pengantar Statistika. Edisi ke-3. Jakarta:PT Gramedia Pustaka Utama.

[5] Closing price. 2013. Available from: http://www.finance.yahoo.com. [diakses pada 2 September 2014].

[6] Uchida, Y. 2008. A Sample proof of the geometric-arithmetic mean inequality. Japan: Okayama Pref.

[7] Schlaifer, R, Johm W.Pratt, Howard.R. 1994. Statistical Desicion Theory. London:The Mil Press.

[8] Luenberger, D.G.1998.Investment Science. Oxford University Press. New York. 